\title{
O PET/Filosofia na Unioeste: um modelo de formação'
}

\author{
The PET/Philosophy in Unioeste: \\ a formation model
}

\section{Resumo}

O que proponho, a seguir, é uma acurada reflexão sobre o papel da Filosofia a partir de três eixos indissociáveis: o ensino, a pesquisa e a extensão. Para tanto, compartilhar-se-á uma singular experiência que, desde 1992, é promovida pelo Curso de Filosofia na UNIOESTE - Campus de Toledo. Trata-se, precisamente, do PET (Programa de Educação Tutorial), uma experiência pioneira que, nas últimas décadas, consolidou-se no país como um modelo exemplar de formação, além de sua proposta multidisciplinar como agente social de fomento.

Palavras-chave: PET/Filosofia; Pesquisa; Ensino; Extensão; UNIOESTE.

\begin{abstract}
What I propose in the following is an accurate reflection on the role of Philosophy from three inseparable axes: teaching, research and extension. In order to do so, we will seek to share a singular experience that, since 1992, as promoted in the Course of Philosophy at UNIOESTE - Toledo Campus. This is precisely the case of the PET (Tutorial Education Program), a pioneering experience that, in the last decades, has consolidated, in the country, itself as a exemplar formation model, in addition to its multidisciplinary proposal as a social agent of development.
\end{abstract}

Keywords: PET/Philosophy; Research; Teaching; Extension; UNIOESTE.

1 Texto parcialmente apresentado na "12 $2^{\mathrm{a}}$ Jornada Paranaense dos Grupos PET, JOPARPET" realizada na UNIOESTE - Campus Toledo, no período de 12 a 14 de outubro de 2018, tendo como temática geral, "O PET como Formação Complementar na Universidade".

* Professor dos cursos de Graduação e de Pós-Graduação (Stricto Sensu) em Filosofia da UNIOESTE -Campus Toledo. E-mail: cafsilva@uol.com.br.

Recebido em: 12/01/2019 Aceito em: 16/07/2019 


\section{Introdução}

Ao retratar a experiência PET (Programa de Educação Tutorial)² do Curso de Filosofia da UNIOESTE, buscarei ensaiar algo muito próximo ao que, convencionalmente, se denomina "relato de experiência". Nesse contexto, eu ainda considerarei um aspecto fundamental, sobretudo, por conta de sua trajetória histórica: a impossibilidade de separar o professor do aluno. Vejo a arte de "aprender" e "ensinar" como dois níveis mutuamente intercalados compondo, pois, um só todo. Isso se torna mais especial em se tratando de um curso de licenciatura como é o de Filosofia. Minha graduação, por exemplo, deu-se integralmente nessa modalidade formativa. O que assegurou ao PET, diferentemente de outros Programas como PIBIC e, mais recentemente, PIBID $^{3}$, é a consolidação de um espaço de formação amplo, de fato, capaz de se integrar mais efetivamente com a pesquisa, a extensão e o ensino. Há uma espécie de vaivém entre ser professor e ser estudante sob o pano de fundo da inserção social que a prática extensionista mormente exige. Falar ora como professor, ora como estudante é dar voz a um só discurso; emancipar uma só

2 Como marco histórico, o PET foi criado em 1979 pela Coordenação de Aperfeiçoamento de Pessoal de Nível Superior (CAPES), significando "Programa Especial de Treinamento". A partir de 1999, essa concepção se reformula substancialmente para além do pioneiro caráter especializado. É o momento em que o Programa é transferido para a Secretaria de Educação Superior (SESu), do Ministério da Educação (MEC) adotando, pois, outra terminologia como "Programa de Educação Tutorial". Oficialmente instituído pela Lei 11.180, de 23 de setembro de 2005, e pela Portaria 3.385, de 29 de setembro de 2005, o PET destina-se a estudantes de cursos de graduação das instituições de ensino superior do país. Entre seus objetivos, o Programa objetiva estimular a formação de profissionais e docentes de elevada qualificação técnica, científica, tecnológica e acadêmica. Trata-se, ainda, de impulsionar o espírito crítico, bem como a atuação profissional pautada pela cidadania e pela função social da educação superior, orientados pelo princípio da indissociabilidade entre ensino, pesquisa e extensão.

3 "Trata-se, portanto, de um Programa que tem um diferencial importante em relação a outros Programas como o PIBIC, por exemplo. Enquanto o PIBIC se limita a um trabalho mais específico ou pontual do ponto de vista estritamente temático da pesquisa, o PET vai além. Ou seja: o PET consubstancia-se numa concepção mais ampla ou vasta, uma vez que não se restringe apenas a uma formação especializada a partir de um autor, de um tema, de uma obra, sob a tutoria ou orientação de um professor. É que o Programa se fundamenta naquilo que se convencionou chamar, no debate público da universidade, de tripé ensino/pesquisa/extensão. Assim, sem perder seguramente seu caráter de especialização, a proposta envolve outras atividades, tais como: estudo de idiomas, participação/organização de eventos, publicação, envolvimento com atividades ligadas ao ensino, ensaios didáticos de formação vinculados à área e, na medida do possível, atividades de extensão, que, na área de Filosofia, diferentemente dos demais campos disciplinares, reveste-se de outro perfil. A extensão é compreendida em nossa área a partir de uma ação mais republicana, isto é, no sentido de 'publicizar' os resultados das pesquisas por meio de seminários, colóquios, congressos, simpósios, semanas acadêmicas, intervenções no debate político, etc. Sob esse prisma, o espírito do PET assume um caráter, de fato, diferenciado uma vez que perspectiva uma concepção mais avançada e, portanto, engajada em termos formativos" (SILVA, C. A. F. "Entrevista": edição comemorativa do Jubileu de Prata do PET/Filosofia. DIAPHONÍA, v. 3 (2), p. 14). 
perspectiva dialógica. O professor jamais pode esquecer que um dia foi aluno; mais que isso, que, de certa maneira, ele continua sendo já que é eterno estudante. Ou, para parafrasear a memorável canção de Milton Nascimento, o coração de um professor nunca deixa de ser um "coração de estudante". Se a vida é, em sentido proverbial, uma escola é porque simultaneamente se aprende e se ensina. Isso significa, entre outras coisas, que a escola, no sentido conferido por Paulo Freire, recria a vida noutra linguagem. O ócio se torna uma arte, uma condição privilegiada desde onde, acima de tudo, se cultiva o pensamento crítico, quer dizer, a reflexão em estado vivo.

Dito isso, me concentrarei, agora, nos três níveis de ações recíprocas que compõem a essência da universidade tendo como referência institucional a experiência do PET/Filosofia na UNIOESTE. O primeiro nível é a pesquisa; o segundo, o ensino; e o terceiro, a extensão gestada à luz desse experimento.

\section{Pesquisa}

O PET/Filosofia na UNIOESTE é uma experiência pioneira em termos de programa alternativo de qualificação acadêmica. Criado em 1992, sob a coordenação do Prof. Dr. Marcos José Müller ${ }^{4}$, hoje docente na UFSC, o Programa é o primeiro institucionalmente implantado já selando 27 anos de história como uma proposta original da qual, tem consolidado, ano a ano, importantes conquistas. No que tange propriamente à pesquisa, o PET alavancou inúmeros projetos ou abordagens temáticas. É sobre elas que buscarei sumariamente reconstituir a partir de diferentes períodos sob a tutoria de pesquisadores do curso que, em geral, têm se alternado a cada triênio, conforme o vínculo com suas respectivas linhas de pesquisa.

4 Aqui cabe o recente testemunho do professor, por ocasião de uma entrevista concedida que contextualiza bem esse momento inaugural do Programa: "Era o ano de 1991. A Unioeste - que à época ainda chamávamos de Facitol - não tinha vínculo algum com as agências de fomento à pesquisa. O edital do PET seria minha primeira tentativa para alcançar financiamento a um projeto de ensino e pesquisa, bem como o primeiro convênio da instituição com a Capes. Estudei o edital, compreendi seu espírito e reconheci nele uma ocasião para aprofundar duas atividades das quais muito gostava: pesquisar e ensinar. Os gestores da instituição deram-me apoio integral. Dos meus colegas recebi muitas sugestões que foram fundamentais para a integralização da proposta. E quando soubemos que a mesma havia sido aprovada, comemoramos muito. Afinal, sabíamos que havíamos inaugurado ali um espaço formal de investigação filosófica que daria visibilidade ao empenho daquele jovem departamento, à qualidade de seus docentes e à diligência dos acadêmicos selecionados. É com muito orgulho que hoje posso dizer que os três acadêmicos que começaram seus estudos no PET em Filosofia da Unioeste são hoje docentes de Filosofia em instituições de ensino superior" (MÜLLER, M. J. "Entrevista", in DIAPHONÍA, v. 2, n. 2, 2016, p. 11-12). 
Nessa retrospectiva, o projeto inaugural concebido pelo PET, levado a termo entre 1992 e 1993, desenvolveu-se a partir de um problema bem específico oriundo da filosofia contemporânea, qual seja, a "Questão Antepredicativa”. Em síntese, a temática deriva de várias fontes de investigações filosóficas (fenomenologia, filosofia analítica, ontologia transcendental) reportando-se, pois, à "investigação de elementos não predicáveis, mas que interagem no processo de predicação" . As obras de autores como Husserl, Heidegger, Merleau-Ponty, Wittgenstein, Ryle e Austin se tornaram importantes fontes desse lastro investigativo trabalhadas em ciclos semestrais de atividades, segundo a dinâmica de reuniões semanais, estudos dirigidos, seminários e colóquios. Vale recordar que tal plataforma de pesquisa teve sua origem na UFRGS sob a coordenação do Prof. Dr. Ernildo Jacob Stein que, aliás, esteve na UNIOESTE, no período de 17 a 30 de agosto de 1992, como Professor Visitante do PET. Na ocasião, ele ministrou o curso "Temas fundamentais de Ser e Tempo de Martin Heidegger", num total de 60 horas/aula. Ademais, Stein proferiu o Ciclo de Conferências "Política, Ciências Sociais e a Filosofia Contemporânea", totalizando 25 horas/aula. É oportuno ressaltar que a figura do Professor Visitante fora, durante certo tempo, uma âncora indispensável na concepção e filosofia do Programa, seja por conta da reconhecida trajetória acadêmico-intelectual na linha de pesquisa afeta, seja pela condução estratégica como coordenador de centros ou grupos de pesquisa de excelência na área.

Em 1993, a tutoria do PET passa ao encargo do Professor Ms. Pedro Gambim, o qual deu continuidade ao planejamento previsto no primeiro biênio. Nesse mesmo ano, o Programa recebe o seu segundo Professor Visitante, o Prof. Dr. Sirio Lopez Velasco, intelectual uruguaio radicado no Brasil e docente na FURG. Ele ministra o Ciclo de Conferências "Ética e Linguagem" no período de 08 a 11 de novembro de 1993, totalizando 16 horas/aula. Entre os módulos trabalhados constam i) Filosofia Analítica da Linguagem e Teoria dos Atos de Fala; ii) Filosofia da Linguagem Ordinária e Ética; iii) Análise Crítica da Ética do Discurso e iv) Ética e Produção". Na verdade, esses Cursos constituíram uma etapa preparatória visando ao segundo planejamento de trabalho do PET.

É assim que, entre o período compreendido entre 1994 e 1999, a pesquisa, no Grupo, passa a concentrar-se em torno de outro eixo temático: a "Questão da Fundamentação Racional na Ética Contemporânea", tendo prioritariamente como referenciais as obras de Karl-Otto Apel e Habermas. Tal 
eixo voltou-se para o exame acerca da possibilidade de uma Ética Discursiva enquanto retomada crítica do ideal kantiano de fundamentação transcendental e, ao mesmo tempo, como movimento teórico que buscara reconhecer, ao nível do discurso e da linguagem, a emergência de uma ética dialógica. Essa nova perspectiva hermenêutica ainda contou novamente com a colaboração do Prof. Dr. Sirio Lopez Velasco que, aliás, vem desenvolvendo um estilo próprio de pensamento com e, para além, da Ética do Discurso de matriz apeliana e habermasiana, caracterizado por ele de "Ética da Produção" ou "Ecomunitarismo"6. Nessa sua segunda vinda, o professor ministrou o curso de extensão "Ética da Produção" entre 13 e 17 de junho de 1994, num total de 20 horas/aula. E em sua terceira vinda, o Ciclo de Conferências "Sobre a Questão da Fundamentação" realizado no período de 17 a 22 de outubro de 1994 com duração de 24 horas/aula.

A partir do período compreendido entre 2000 e 2005, o planejamento das atividades reorientou-se teoricamente via outras interlocuções no campo da reflexão ética contemporânea. Três foram os principais autores abordados: John Rawls, Ernst Tugendhat e Levinas. Em síntese, entre 2000 e 2001, o Grupo concentrou-se sobre a teoria rawlsiana da justiça como equidade (justice as fairness), a qual busca estabelecer princípios fundantes de uma sociedade bem ordenada. O texto central trabalhado foi o clássico A Theory of Justice (1971). Acerca de Tugendhat, a pesquisa se deteve, particularmente, na proposta de uma "moral do respeito universal". As obras básicas reportadas foram os Problemas de la ética (1988) e as Lições sobre Ética (1996). Por fim, em torno de Levinas, o professor-tutor ministrou 20 horas de preleções introdutórias à obra do pensador lituano, com vistas a esclarecer conceitos fundamentais e procedimentos epistemológico-argumentativos. Após esta etapa, ocorreram encontros semanais de estudo e leitura dirigida de textos selecionados do referido filósofo visando ao aprofundamento de temas e categorias sob o horizonte da Ética como Filosofia Primeira. Nessa medida, a investigação voltou-se para a análise do estatuto da crítica levinasiana à ontologia fundamental, bem como à compreensão da constituição da subjetividade como "sensibilidade" enquanto pulsão de "alteridade", origem da responsabilidade pelo Outro, anterior a toda ordem social.

6 Ver, subsequentemente, LOPEZ VELASCO, S. Reflexões sobre a filosofia da libertação. Campo Grande, MS: CEFIL, 1991; Idem, Ética de la producción: fundamentos. Campo Grande: CEFIL, 1994; Idem, Fundamentos lógico-linguísticos da ética argumentativa. São Leopoldo, RS: Nova Harmonia, 2003; Idem, Ideias para o socialismo do século XXI com visão marxiana-ecomunitarista. Rio Grande, RS: Editora FURG, 2012 e Idem, Contribuição à teoria da democracia: uma perspectiva ecomunitarista. Porto Alegre: FI, 2017. 
A partir de 2006, o Programa passa a ser tutorado pelo Prof. Dr. César Augusto Battisti tendo em vista outro eixo temático - "A Questão da Subjetividade" - mediante, principalmente, as obras de Descartes e Kant. Um dos resultados materializados desse trabalho foi a coletânea organizada pelo tutor, Às voltas com a questão do sujeito: posições e perspectivas, coeditada pela Edunioeste e Editora da UNIJUí, em $2010^{7}$, reunindo pesquisadores de outras instituições que, direta ou indiretamente, envolveram-se com as atividades do PET. Vale registrar que fora uma política recorrente do Programa a criação de um banco de resenhas, artigos ou textos produzidos por meio das pesquisas dos próprios membros petianos, além de franquear acesso, em parceria, com estudiosos externos.

Ainda em torno da pesquisa, há de se considerar que cada bolsista define uma questão temática de seu interesse, alinhada com o filósofo de referência. O trabalho é orientado por um professor do curso, consistindo, portanto, em várias etapas: levantamento bibliográfico de fontes primárias e secundárias; leitura desses materiais; redação de textos; discussão em grupos de estudos; apresentação e publicação em anais e/ou revistas. Há, evidentemente, pesquisas em níveis distintos, dependendo da série em que se encontra o bolsista e do tempo que integra o Grupo.

Em tal contexto, a pesquisa só poderá lograr êxito se for conjugada com outras atividades essenciais. A primeira delas é a oficina de "Português Instrumental: leitura e produção de textos filosóficos". O interesse nessa iniciativa deve-se às limitações, cada vez crescentes, quanto ao trato da língua materna entre os estudantes que chegam à universidade. Com raras exceções, a quase totalidade desse público se depara com enormes deficiências de escrita, de conhecimento elementar de gramática, etc. Prova disso é o significativo tempo que o professor dispensa em se dedicar quase que, de modo exclusivo, às correções linguísticas ou problemas estilísticos do que, primordialmente, o conteúdo filosófico. Ora, em Filosofia, essencialmente, não se trabalha com cálculos ou estatísticas, mas com argumentos, questões, conceitos, etc. A clareza argumentativa aliada a um bom domínio do idioma vernáculo é um princípio indispensável da práxis filosófica. É visando, pois, a atender essa demanda que a oficina intervém como um instrumento qualitativo da formação.

Paralelamente a esse trabalho, os bolsistas também se integram em cursos de idiomas ofertados pela própria universidade ou por escolas privadas de 
ensino, bem como recebem aulas particulares ou na modalidade on line. De todo modo, são realizadas oficinas de tradução sob a responsabilidade de um professor do Curso com maior experiência, no intuito de já criar as condições mínimas de acesso ao conhecimento das regras básicas de tradução, contribuindo para o desenvolvimento das habilidades de leitura em língua estrangeira. Como critério, a definição do idioma a ser cursado se vincula, fundamentalmente, à necessidade mais imediata dos discentes na leitura dos autores clássicos estudados.

Os eventos também constituem, sobremaneira, atividades integrantes da pesquisa. Nessa direção, tanto os bolsistas quanto o corpo discente em geral são, a todo tempo, instigados a organizar e participar de eventos locais e nacionais como ENEFIL e ANPOF. Na UNIOESTE, são dois, ao menos, os principais eventos promovidos com programação anualmente ininterrupta: a "Semana Acadêmica de Filosofia", tradicionalmente editada no primeiro semestre e o "Simpósio de Filosofia Moderna e Contemporânea" que, comumente, transcorre entre os meses de outubro e novembro. A Semana Acadêmica tem assumido um perfil mais singular nos últimos anos ao refletir, preferencialmente, sobre a problemática do ensino de Filosofia na educação básica. Isso tudo sem perder a perspectiva de um debate mais plural e transversal às demais áreas. No caso específico do Simpósio, em virtude de seu caráter internacional que conjuga conferências, minicursos e comunicações, o PET tem marcado forte presença.

O Prof. Dr. Wilson Antonio Frezzatti Jr assumiu a coordenação do Programa no período compreendido entre abril de 2010 e março de 2013, tendo como escopo geral a temática "Natureza x Cultura". O eixo concentrou-se no estudo de diferentes pensadores, tais como Aristóteles, Hegel, Nietzsche, Darwin, Heidegger e Merleau-Ponty. A maioria deles foram abordados pelos bolsistas em suas pesquisas individuais sob orientação dos professores do Curso.

Já de abril de 2013 a março de 2016, assume a coordenação o Prof. Dr. Claudinei Aparecido de Freitas da Silva. O projeto proposto - "Filosofia: seus sentidos e sua importância" - focou-se nas inúmeras concepções temáticas que se delineiam ao longo da História da Filosofia, entrecruzando-se com questões basilares que vão desde a metafísica, passando pela ética, pela filosofia política, pela estética, pela epistemologia, pela lógica, até culminar na filosofia da linguagem. Desse planejamento trienal ganha destaque a criação, em 2015, de um projeto editorial pioneiro na universidade: a revista DIAPHONÍA 
[ISSN 2446-7413]. Inspirando-se nos Cadernos de Estudos Petianos (1996 $1997^{9}$ e $2007^{10}$ ) veiculados, em três edições, sob a organização do segundo tutor, Pedro Gambim, a Revista projeta-se como o primeiro periódico institucional com um caráter diferenciado, ou seja, o de suprir uma demanda reprimida entre os acadêmicos graduandos, haja vista que, em geral, esses veículos são seletivamente destinados à pós-graduação e aos pesquisadores doutores. Fato é que, no país, observa-se cada vez mais um considerável crescimento da produção discente em nível de graduação (seja via iniciação científica, seja por meio de programas de formação como o próprio PET e PIBID). Objetivamente, há, ainda, um diminuto espaço institucional para isso, com, é claro, raras exceções. É objetivando sanar tal carência que a DIAPHONÍA, então, surge, reafirmando a vocação primordial do Programa e, desse modo, marcando uma posição qualificada em termos de produtividade de pesquisa no contexto nacional da área ao espelhar o processo de formação de seus autores.

Já no triênio compreendido entre abril de 2016 e março de 2019 assume a coordenação a Prof. ${ }^{a}$ Dr. ${ }^{a}$ Ester Maria Dreher Heuser. O projeto por ela tutorado intitula-se "Filosofia e suas fronteiras: literatura, artes e ciências". Em síntese, a proposta consistiu em nuclear as diferentes atividades em torno das relações entre filosofia e literatura (no primeiro ano), das relações entre filosofia e artes (no segundo ano) e, por fim, as relações entre filosofia e ciências.

É sob este contexto mais abrangente, concebido a partir de diferentes planejamentos, que o horizonte de trabalho do PET não tem se limitado apenas à atividade de pesquisa, mas se desdobrado criativamente noutro nível ou modalidade: o ensino.

\section{Ensino}

Pode-se partir, agora, a propósito da experiência genuinamente pedagógica em Filosofia, de uma longa e curiosa observação feita por Heidegger. Em tese, avalia ele:

É bem sabido que ensinar é ainda mais difícil que aprender. Mas raramente se pensa nisso. Por que ensinar é mais difícil que aprender? Não porque o

\footnotetext{
8 GAMBIM, P. (Org.). Cadernos de estudos petianos. Toledo, PR: Unioeste, 1996, Ano 1, nº 1.

9 GAMBIM, P. (Org.). Cadernos de estudos petianos. 2. ed. Cascavel, PR: Edunioeste, 1997.

10 GAMBIM, P. (Org.). Cadernos de estudos petianos. 3. ed. Cascavel, PR: Edunioeste, 2007.
} 
mestre deva possuir um maior acervo de conhecimentos e os ter sempre à disposição. Ensinar é mais difícil do que aprender, porque ensinar quer dizer "deixar aprender". Aquele que verdadeiramente ensina não faz aprender nenhuma outra coisa que não seja o aprender. É por isso que o seu fazer causa muitas vezes a impressão que junto dele nada se aprende. Isso acontece porque inconsideradamente entendemos por "aprender" a só aquisição de conhecimentos utilizáveis. O mestre que ensina ultrapassa os alunos que aprendem somente nisto: que ele deve aprender ainda muito mais do que eles, porque deve aprender a "deixar aprender". O mestre deve poder ser mais ensinável que os alunos. O mestre é muito menos seguro de seu ofício que os alunos do seu. Por isso, no relacionamento do mestre que ensina e dos alunos que aprendem, quando o relacionamento for verdadeiro, jamais entram em jogo a autoridade de quem sabe muito bem nem a influência autoritária do representante magisterial. Por causa disso é ainda uma grandeza ser mestre - que é bem outra coisa que ser professor célebre. Se hoje - onde tudo é medido sobre o que é baixo e conforme ao que é baixo, por exemplo, sobre o lucro - ninguém mais deseja ser mestre, isso é devido, sem dúvida, ao que essa grande "coisa" implica e à grandeza de si própria. ${ }^{11}$

Heidegger fornece, em primeira mão, bem mais que uma mera cartilha pedagógica. Quer dizer, ele retrata um relato de experiência com profunda probidade não só intelectual, mas acerca da natureza do paciente trabalho que envolve o "fazer" e o "aprender" filosófico. Tudo se passa como se o ensino propriamente dito, mais que uma simples transmissão de conteúdos, se revelasse, originariamente, como uma arte; arte no sentido de um ouvir permanente, isto é, de perceber o que se passa ao redor de um cenário em que os principais personagens envolvidos (mestre e aluno) tomam parte facticamente. O que Heidegger nos faz pensar é que, nessa íntima relação, outra ordem de diálogo é permeada por certa disciplina e devoção à tarefa do pensamento. Essa tarefa se consubstancia na junção da arte do ensino/aprendizagem com a da pesquisa. É nesse sentido que o professor se sente mais "inseguro" do que o próprio aluno, já que aí não reside mais a autoridade institucional burocrática ou autoritária de quem ensina. Ser professor é muito mais que ocupar uma cátedra ou possuir certa notoriedade acadêmica. É abrir mão de qualquer presunção dessa ordem assegurando, no âmbito da práxis pedagógica, o livre pensar. Ora, é imbuído desse espírito que o PET, desde a sua

11 HEIDEGGER, Qu' appelle-t-on penser 1973, p. 89 
fundação, buscou encarnar um ideal a ser perseguido. A relação do tutor com os acadêmicos tem procurado transcender toda polarização educacional, já que, nessa proposta, não se trata simplesmente, como lembrara Heidegger, de reproduzir conteúdo, menos ainda de formar discípulos. Cabe ao acadêmico desenvolver um perfil mais autônomo e, por isso mesmo, tomar as rédeas de sua própria formação numa perspectiva de livre investigação. O estudante, se tem algo a aprender, é o "caminhar com as próprias pernas", quer dizer, construir seu percurso de reflexão visando sempre a sua emancipação intelectual. Para que essa conquista se torne exequível será preciso, como exortara Heidegger, que o "mestre" (no caso, em questão, o tutor) seja realmente capaz de reconhecer que necessita "aprender ainda muito mais do que o aluno, justamente porque deve aprender a 'deixar aprender". Só assim como também se reportara Merleau-Ponty, "filosofar é reaprender a ver de novo"12 instituindo, portanto, uma real experiência de pensamento como criação, acontecimento liberto, pois, de todo engessamento ou academicismo esterilizante.

É este horizonte mais amplo que tem norteado o PET na Filosofia como proposta alternativa e, portanto, "afirmativa" de formação acadêmica. Nessa direção, tal vivência revelou que o Programa contribuiu, de fato, para a promoção de quaisquer iniciativas de alunos que ousaram dar continuidade tanto às suas pesquisas em etapas vindouras, ao se inserirem em inúmeros programas de pós-graduação, quanto à tarefa como professores na rede básica de ensino. Boa parte desse contingente de ex-bolsistas ou já está exercendo o magistério do ensino médio ou atuando como pesquisadores e professores universitários (após a conclusão de seus respectivos doutorados e/ou mestrados) cumprindo, assim, a política de verticalização formativa do PET.

Não deixa de ser oportuno acrescentar, do ponto de vista didático, outras importantes iniciativas desse modelo experimental. Uma delas é o projeto "Plantão PET" em que os bolsistas junto ao CAFIL (Centro Acadêmico do Curso de Filosofia) se dispõem a acompanhar e auxiliar os demais estudantes da área, sobretudo os calouros, seja relativamente às informações acadêmicas (aquisição de bolsas, projeto político-pedagógico, manual das normas), seja quanto ao trabalho de monitoria ou orientação de pesquisa. A atuação voluntária dos bolsistas como monitores junto aos colegas de graduação tem exigido, como é da essência da licenciatura, a construção de metodologias de ensino, propiciando, desde então, um ambiente propedêutico à própria prática de estágio que ocorre a partir do terceiro ano de formação. 
O "Ciclo de Palestras" é outra atividade para a qual, anualmente, são convidados, professores do curso ou pesquisadores externos. Ela objetiva cobrir lacunas sobre determinados temas pouco abordados na grade curricular. Além disso, o Ciclo é aberto à comunidade acadêmica e à sociedade em geral. Dele se desdobra ainda uma segunda atividade que são os "Seminários" preparados pelos bolsistas a partir de textos previamente indicados pelos palestrantes.

A bem da verdade, tais medidas visam proporcionar, como destaca o ex-tutor César A. Battisti,

Um espaço de auxílio e de integração aos alunos da primeira série do Curso e, ocasionalmente, de outras séries. A proposta de plantão visa ajudá-los tanto do ponto de vista acadêmico quanto sobre questões formais e administrativas que lhe são pertinentes. Prioritariamente, a orientação recairá sobre questões de conteúdo e voltadas às disciplinas que os interessados estão cursando. Para orientá-los, os bolsistas terão à disposição o plano de ensino das disciplinas da primeira série e manterão contato com os respectivos professores [...]. A atividade é uma novidade para os bolsistas que atuarão como monitores, de modo que eles terão que perceber a necessidade dos alunos, suas carências e dificuldades. Além disso, a efetividade e o sucesso da atividade dependerão da procura por parte dos alunos interessados. ${ }^{13}$

Nessa proposta, a integração do Programa com a graduação é dinamicamente incentivada e sistematicamente avaliada. O que se espera é que os bolsistas atuem exemplarmente no circuito mais vasto da vida universitária, firmando uma postura desinteressada, ou seja, desprovida de qualquer posição autocrática ou vantagem frente aos demais colegas de formação. Assim, como seus mestres, o acadêmico petiano deve assumir, com afinco, outro perfil: o de, na condição de aprendiz, despertar junto aos seus pares valores como a da solidariedade intelectual, incutindo-lhes o sentimento de motivação pelo fazer filosófico. É preciso evitar, a qualquer custo, certo vício comum no ambiente universitário, o do "estrelismo acadêmico"; atitude da qual só contrariaria, sintomaticamente, a virtude apontada por Heidegger que se espera, portanto, de uma relação verdadeiramente pedagógica. Ora, o que entra em jogo nessa experiência é a possibilidade de se pensar outro modelo educacional para a universidade preservando, ao mesmo tempo, a interação contínua entre os

13 BATTISTI, MEC/SESu: planejamento anual de atividades do PET/Filosofia da UNIOESTE, 2008/2009, p. 14. 
bolsistas no conjunto do corpo discente e docente tanto na graduação quanto na pós-graduação. Conforme prevê o "Manual de Orientações Básicas - PET" editado pelo MEC/SESu, em 2002 (p. 4),

As atividades extracurriculares que compõem o Programa têm como objetivo garantir aos alunos do curso oportunidades de vivenciar experiências não presentes em estruturas curriculares convencionais, visando a sua formação global e favorecendo a formação acadêmica, tanto para a integração no mercado profissional como para o desenvolvimento de estudos em programas de pós-graduação.

Tais reorientações pedagógicas não se dissociam de outra frente de atuação absolutamente indispensável, isto é, marcadamente extensionista, consolidando a tríade ensino, pesquisa e extensão como base da formação acadêmica.

\section{Extensão}

Do ponto de vista da atividade extensional, inúmeros são também os projetos realizados. Entre estes, vale destacar a KULA Webradio universitária, um canal radiofônico digital sediado no campus de Toledo, no seguinte sítio: http:// www.unioeste.br/webradio/. Desse modo é que, desde 2009, sob a coordenação do ex-tutor Wilson A. Frezzatti Jr., foi ao ar o Programa The Blue Soul of Blues, às terças-feiras, às 19:20hs. O programa, de difusão cultural, mescla estilos musicais como o Blues com a própria história do Blues, além de poesia e reflexões sobre a melancolia, tendo por objetivo geral, pensar a relação da Filosofia com a Arte e a finitude humana, a história, a resistência cultural e as questões sociais manifestas nesse gênero musical.

Dignos de menção são os saraus e rodas de conversas temáticas nos quais o Grupo se envolve periodicamente. Basicamente, nessa atividade coordenada pela ex-tutora Ester Maria Dreher Heuser, são selecionados contos, ensaios breves e poemas produzidos por escritores clássicos e/ou contemporâneos. Tais encontros são organizados durante o período noturno para leitura, recitação e debate.

O PET tem tomado corpo em outras iniciativas culturais como as voltadas para a produção cinematográfica. Exemplo disso são o "Ciclo Internacional de Curtas-Metragens" e o projeto "Cinema Latino-Americano", idealizado em parceria com o Curso de Ciências Sociais. Por meio dessas atividades transcorridas no período entre 2007 e 2014, o Programa alavancou seu papel 
acadêmico no contexto de uma política de maior integração sociocultural.

Outro projeto é "A difusão do curso de Filosofia junto a estudantes do ensino médio". Essa medida busca colocar os petianos em contato com a formação estudantil secundarista, tendo como intuito a divulgação do Curso de Filosofia da universidade. Os bolsistas do PET se integram ao cronograma de ações planejadas pela instituição e coordenação do Colegiado de Curso. Tem-se formada, de tempos em tempos, a convicção de que essa interação se revela vital à medida que põe em prática a vivência da licenciatura, isto é, as próprias metodologias são testadas diante dos avanços e desafios do Ensino de Filosofia.

Nesse contexto, não se pode negligenciar em função, sobretudo, da presença da disciplina de Filosofia na educação básica uma aposta importante dessa experiência: o projeto "Perspectivas filosóficas para a educação inclusiva". Trata-se, na verdade, de um projeto piloto oriundo da parceria entre a UNIOESTE e a Secretaria Municipal de Educação de Toledo, por meio da licenciatura em Filosofia. A proposta consiste em oferecer curso de formação continuada para professores e psicopedagogos da rede pública de ensino que trabalham com crianças portadoras de necessidades especiais e crianças diagnosticadas com Altas Habilidades/Superdotação. Tendo como enfoque a educação inclusiva, a atividade se subsidia em pressupostos teórico-metodológicos formulados pelo pensador norte-americano Matthew Lipman (1923-2010), idealizador do programa "Filosofia para crianças"14. Primordialmente voltada para o pensar lógico-crítico, ético e criativo, o projeto encampa a prática de estudos individuais e sua respectiva reflexão coletiva em encontros e palestras, propondo procedimentos que possam ser desenvolvidos com as crianças.

No sentido de fortalecer os laços com outros programas do gênero na universidade, dada a sua estrutura multicampi, foi concebido o UNIPET (Encontro dos Grupos PET da UNIOESTE). Trata-se de um fórum permanente de debate acerca das demandas internas e externas que envolvem o próprio Programa como um todo. A iniciativa surge de um longo período de ciclos instáveis frente aos desafios e expectativas no afã de assegurar uma maior integração da comunidade petiana. Ademais, a parceria junto à Iniciação Científica (PIBIC) e o PIBID vem consolidando fortemente o caráter multidisciplinar que caracteriza a vocação intrínseca do PET.

14 Trata-se, respectivamente, dos livros: LIPMAN, M. A filosofia vai à escola. Trad. Maria Elice de Brzezinski Prestes e Lucia Maria Silva Kremer. 3. ed. São Paulo: Summus Editorial, 1990 e Idem, O pensar na educação. Trad. Ann Mary F. Perpétuo. Petrópolis, RJ: Vozes, 1995. 


\section{Filosofia e conjuntura política}

Um dos desdobramentos da extensão em Filosofia refere-se ao espaço a ela reservado hoje, em termos políticos. Por isso, para além do tripé antes reconstituído, há outro elemento estratégico quando se trata de situar o PET: a conjuntura política. Isso pode ser apontado não porque estamos atravessando mais um momento consideravelmente delicado da história nacional (com repercussões, inclusive, internacionais), mas porque a partir do instante em que foi concebido ainda no final da década de 1970, o Programa acompanhara essa mesma história. Noutros termos, tratava-se, à época, de um modelo de formação cuja capilaridade se estenderia a par do cenário político em curso. Fato é que, em suas múltiplas configurações desde a origem, o PET termina por refletir, inequivocamente, esse cenário. Disso advém a importância de recuperar um pouco, mesmo que brevemente, a história. Resgatar a memória histórica é não perder de vista o passado que nos pertence, o presente que nos desafia e o futuro que nos acerca.

Nesse panorama, cabe registrar algo que, volta e meia, é esquecido ou, sequer, observado. O PET nasce, curiosamente, num período de resistência à ditadura. É o momento em que se inicia um processo de redemocratização do país, particularmente, com o movimento das Diretas Já. Diversamente do que, em regra, se pensa, o país não conseguiu exorcizar, de vez, o fantasma desses tempos sombrios. Não se acertou devidamente as contas com esse passado histórico, razão pela qual o Brasil se vê diante de um "estado de exceção" que põe gravemente em risco projetos educacionais como o PET, a exemplo do que ocorrera com o PIBID, entre outros programas.

Sob esse prisma, não se pode esquecer de que, entre 1994 e 2002, o PET quase fora extinto se não ocorresse o incansável trabalho de resistência encampado por um movimento ainda informal de agentes nesse processo que, poucos anos depois, deu origem ao CENAPET em rede nacional ${ }^{15}$. Muitos foram

15 "A CENAPET é a entidade representativa dos estudantes e professores-tutores no contexto do Programa de Educação Tutorial, sendo que esta tem a função de representar a comunidade petiana e realizar a comunicação com órgãos superiores como o MEC. A CENAPET foi fundada em 2006 durante a realização do ENAPET de Florianópolis, quando foram aprovados seu estatuto e regimento. A Diretoria eleita foi presidida pelo Prof. Dante Barone. No entanto, antes deste período, existia informalmente um grupo de pessoas, tutores e alunos reunidos sob uma Executiva Nacional, que foi se formando nos anos de luta contra a extinção do PET, desde 1998. Parte deste grupo compôs a CNAA, Comissão Nacional de Acompanhamento e Avaliação, no MEC-SESu, em 2002, que recuperou o processo de avaliação, revisão do Manual de Orientações Básicas, etc." (VVAA. "Apresentação/Histórico do CENAPET", in https://cenapet.wordpress.com/ cenapet-4/apresentacaohistorico/). 
os congressos, debates públicos aliados a uma política (no sentido "sindical" do termo) que mobilizou, aguerridamente, centenas de pesquisadores e estudantes universitários. No caso particular da Filosofia, então, nem se fale, pois já, a essa altura, reinicia-se, fervorosamente, todo um movimento, em parceria com a Sociologia, no intuito de implementar tais disciplinas no currículo de ensino médio. Nunca é demais recordar que se Fernando Henrique Cardoso, sociólogo de formação, vetou a inclusão desses conteúdos formativos, o governo Lula assim os chancelou tornando-os obrigatórios ${ }^{16}$. Esse registro se torna importante na medida em que significativos avanços na concepção do PET como modelo de formação se refletirão diretamente na própria Filosofia. No Brasil, além da UNIOESTE, várias outras instituições se beneficiaram dessa experiência na área como, por exemplo, a UFPR, a UFMG, a UFPI, a USP.

Frente a esse contexto, há outra pauta programática não desprezível: o orçamento destinado à educação. Há uma luta crescente em termos de recursos. Em alguns governos, a educação é mais vista como despesa do que investimento. Esse quadro geral tem, inevitavelmente, provocado uma instabilidade quanto à manutenção do PET, apesar de alguns esforços em assegurar a continuidade do Programa ${ }^{17}$. De todo modo, o fator crucial é que nos últimos anos não se tem aberto mais programas e os que ainda permanecem resistem. O PET/Filosofia da UNIOESTE tem sido, nessa perspectiva, um agente de resistência. Afora os parcos recursos federais disponibilizados, algumas

16 Para uma maior compreensão acerca do contexto em que se dá esse veto, ver: SILVA, C. A. F. "O 'retorno' da "coruja”, in Tempo da Ciência (UNIOESTE), v. 14, p. 45-57, 2\%/Sem, 2007.

17 Desde o seu início, sob a presidência da CAPES e, posteriormente, a partir de dezembro de 1999, sob a coordenação da Secretaria de Educação Superior - SESu/MEC, é atribuída ao PET uma cota de bolsas cujos valores são fixados em nível nacional e repassados às Pró-Reitorias de Graduação ou órgão equivalente. Os valores das bolsas do Professor Tutor, após a identificação da forma legal de remuneração, correspondem ao valor integral de uma bolsa de doutorado e, do aluno, correspondem ao valor integral da bolsa de Iniciação Científica (PIBIC) do CNPq/MCT. O SESu/MEC também concede ao Programa taxas acadêmicas destinadas a cobrir parte das despesas relativas às atividades do grupo, bem como passagens para os professores e acadêmicos visitantes. Dessa forma, "A SESu apoiará apenas uma solicitação por grupo, a cada ano, exclusivamente dentro do território nacional. A SESu subsidiará as passagens e uma ajuda de custo para o professor visitante, de acordo com sua disponibilidade orçamentária e financeira. Assim, a previsão da visita do professor visitante deverá constar no 'Plano de Atividades' do grupo e será, portanto, analisada pelo Comitê Local de Acompanhamento PET. Para isto, o grupo deverá informar os objetivos gerais da visita e apresentar um planejamento global de atividades, bem como indicar, os nomes de possíveis visitantes, com especificação da sua instituição de origem, titulação e área de atuação. Além disso, visando o desenvolvimento de programas de integração regional e de apoio a grupos emergentes, principalmente em regiões em que há reduzido número de grupos, será possível a troca de experiências com as instituições mais desenvolvidas através de visitas de estudantes e professores”. (VVAA. MEC-SESu. Manual de Orientações Básicas - PET, 2002, p. 21). 
ações internas foram implementadas principalmente em períodos anteriores em função de cortes de bolsas ou taxas acadêmicas (verbas de custeio). Assim, por exemplo, do ponto de vista da estrutura física, a universidade tem alocado espaço reservado ao Programa, com instalações adequadas, mobília, rede de computadores, novos periféricos, livros, dicionários, obras de referência, etc. Boa parte dessa infraestrutura é também compartilhada pelo colegiado de graduação e pós-graduação stricto sensu do Curso.

\section{Conclusão}

Como sumariamente acompanhou-se até aqui, cada uma das modalidades (pesquisa, ensino e extensão) não representam três níveis estanques, mas compõem, indissociavelmente, o corpo e a alma do PET em plena sintonia com o espírito maior pelo qual se define a universidade. Ao mesmo tempo, convém frisar que essa política conjunta não é exequível sem um empenho vigoroso e, portanto, mais harmonioso de todos os atores envolvidos. Idealizar, planejar e realizar são objetivos que têm representado um desafio permanente a esse modelo alternativo de formação acadêmica.

Tem sido graças à sua resistência política e acadêmica que o PET/Filosofia da UNIOESTE galgou importante consolidação em tempos tão bicudos. Essa força-tarefa terminou por assegurar a qualidade acadêmica da pesquisa filosófica sem deixar de firmar sua posição estratégica ao longo de quase 30 anos de existência. Historicamente, trata-se, sem dúvida, de uma experiência altaneira, inovadora e multiplicadora. A Filosofia, como vimos, se beneficiou consideravelmente dessa proposta, em que pese o fato de as áreas humanísticas sofrerem uma aviltante depreciação orçamentária comparável, como é de praxe, ao financiamento repassado às demais áreas. Neste contexto não muito parcimonioso, a proposição do PET assume ainda mais um papel político inestimável sem deixar de alavancar sua missão pedagógica e multidisciplinar. É nesse terreno que a Filosofia, mais do que nunca, pode agir como crítica não só acadêmica, mas profundamente social.

Enfim, ao instituir-se como programa de vanguarda em termos de formação na universidade, o PET amadureceu, mostrando a que veio. Seus frutos são hoje reconhecidos em todas as áreas do conhecimento. A Filosofia, em particular, se reinventou significativamente ao repensar a sua presença na academia via também essa insigne experiência formativa. O que mais se espera é que as novas políticas educacionais não põem a perder o que se conquistou, durante décadas, com tanto trabalho e esmero. 


\section{Referências}

BATTISTI, C. A. (Org.). MEC/SESu: planejamento anual de atividades do PET/Filosofia da UNIOESTE. Toledo, PR: 2008/2009, 23p.

Às voltas com a questão do sujeito: posições e perspectivas. Cascavel, PR/Ijuí, RS: Edunioeste/Editora da UNIJUí, 2010.

GAMBIM, P. (Org.). Cadernos de estudos petianos. Toledo, PR: Unioeste, 1996, Ano 1, no 1 . Cadernos de estudos petianos. 2. ed. Cascavel, PR: Edunioeste, 1997. Cadernos de estudos petianos. 3. ed. Cascavel, PR: Edunioeste, 2007.

HEIDEGGER, M. Qu' appelle-t-on penser. Paris: Gallimard, 1973.

LOPEZ VELASCO, S. Reflexões sobre a filosofia da libertação. Campo Grande, MS: CEFIL, 1991.

Ética de la producción: fundamentos. Campo Grande: CEFIL, 1994.

Fundamentos lógico-linguísticos da ética argumentativa. São Leopoldo, RS: Nova Harmonia, 2003.

Ideias para o socialismo do século XXI com visão marxiana-ecomunitarista. Rio Grande, RS: Editora FURG, 2012.

Contribuição à teoria da democracia: uma perspectiva ecomunitarista. Porto Alegre: FI, 2017.

LIPMAN, M. A filosofia vai à escola. Trad. Maria Elice de Brzezinski Prestes e Lucia Maria Silva Kremer. 3. ed. São Paulo: Summus Editorial, 1990.

O pensar na educação. Trad. Ann Mary F. Perpétuo. Petrópolis, RJ: Vozes, 1995.

MERLEAU-PONTY, M. Phénoménologie de la perception. Paris: Gallimard, 1945.

MÜLLER, M. J. "Filosofia abre caminhos", in Informativo UNIOESTE, Jornal do Oeste (Toledo-PR), ago/1992, p. 11.

"Entrevista", in DIAPHONÍA, v. 2, n. 2, p. 2016, p. 11-14.

RAWLS, J. A theory of justice. Cambridge: Harvard University Press, 1971.

SILVA, C. A. F. "O 'retorno' da "coruja", in Tempo da Ciência (UNIOESTE), v. 14, p. 45-57, 2\% Sem, 2007.

"Entrevista": edição comemorativa do Jubileu de Prata do PET/Filosofia. DIAPHONÍA, v. 3, n. 2, p. 12-20, 2017.

TUGENDHAT, E. Problemas de la etica. Barcelona: Critica, 1988.

Lições sobre Ética. Petrópolis, RJ: Vozes, 1996.

VVAA. MEC-SESu. Manual de Orientações Básicas - PET, 2002, 28pp.

VVAA. "Apresentação/Histórico do CENAPET", in https://cenapet.wordpress.com/ cenapet-4/apresentacaohistorico/. Acesso em: 03 jul. 2019. 